\title{
The use of color duplex in precise preoperative planning of the anterolateral thigh (ALT) perforator flap
}

\author{
Basim M Zaki, ${ }^{a} M D$; Sherif H Abo Gamrah, ${ }^{b} M D$; Ayman A Shaker, ${ }^{a} M D$; \\ Mustafa M Hemeda, ${ }^{a} M D$
}

\author{
a) Department of Plastic and Reconstructive Surgery, Ain Shams University, \\ Cairo, Egypt. \\ b) Department of Radiology, El-Mataria Teaching Hospital, Cairo, Egypt.
}

\begin{abstract}
Perforator flaps from the thigh region carry many advantages in the reconstructive paradigm, yet they still have some disadvantages, mainly variation in the vascular anatomy. The current study was conducted on nine patients planned for anterolateral thigh flap elevation and were examined preoperatively by doppler, color duplex and angiographic studies.

Results: It was found that there was a statistically significant difference between the number of perforators detected by doppler and those detected by color duplex on either side; all perforators that were detected by preoperative color duplex examination were found intraoperatively although in one patient the perforator was detected further away from the planned site. The duplex alone could be a reliable tool in detecting \& locating perforators accurately giving the surgeon enough data about the perforator's anatomy necessary for performing the procedure and elevating the flap safely and promptly.

Conclusion: Color Duplex alone is a reliable method for detection of the perforators of the anterolateral thigh flap.
\end{abstract}

\section{Introduction:}

The anterolateral thigh (ALT) flap has many advantages, but the primary advantage is minimization of donor site morbidity since fascia, muscle and nerves can be preserved. The main pedicle may not be needed when the length of the perforator is sufficient and the diameter of its proximal end is large enough to perform a microvascular anastomosis. ${ }^{1}$ However, the anterolateral thigh flap has not come into widespread use since surgeons can not accurately predict the number and location of the cutaneous perforators which vary individually; this makes flap dissection often more complicated than other flaps. ${ }^{1}$ In addition, this flap has some disadvantages such as hair growth in some male patients and bulkiness of the flap. ${ }^{2}$

The anterolateral thigh (ALT) flap was first reported by Song et al. ${ }^{3}$ According to their report, this flap is supplied by a septocutaneous perforating artery in the proximal one-third of the lateral thigh. This perforator arises from the descending branch of the lateral circumflex femoral artery (LCFA) and passes through the intermuscular space between the rectus femoris and vastus lateralis muscles towards the fascia lata and skin. As the vessel proceeds downwards, in addition to giving branches to the rectus femoris, vastus lateralis and tensor fascia latae muscles, it also sends cutaneous branches to supply the skin over the anterolateral aspect of the thigh. There are often accessory muscle perforators proximal or distal to the main septocutaneous perforating artery.

Identifying the suitable perforators by a reliable method is the key for successful elevation of flaps. In their technique, Song et al. ${ }^{3}$ preoperatively located and marked the position of the vascular pedicle by Doppler flowmetry. Koshima et al., ${ }^{4}$ reported failure to find perforators in 5 of 13 cases and documented variations in the perforator origin either from the descending branch of the lateral circumflex femoral artery or arising from the 
profunda femoris artery. In their study, Zhou et al., 5 reported that the majority of perforators were derived from the descending branch of the lateral circumflex femoral artery while a small percent arose from the transverse branch of the lateral circumflex artery. In a later study by Koshima et al., ${ }^{6}$ elevation of the anterolateral thigh flap was guided preoperatively using Doppler and angiography.

Taylor et al., ${ }^{7}$ and others improved preoperative flap planning by using the acoustic Doppler probe to locate the vascular perforators in many different flaps, but proved that it does not allow visualization of the vessel or its caliber in addition to the high false positive results. Color duplex examination is another tool for preoperative identification of perforators. It has been used by Iida et al., ${ }^{1}$ and Tsukino et al., ${ }^{8}$ who reported that this method is significantly more accurate than the acoustic Doppler examination in the preoperative mapping of perforators. They also reported that this method can detect the number, caliber and course of these perforators. Although sensitivity is high, color duplex imaging has low specificity because only a given region can be examined at any one time in addition to the difficulty of transferring the duplex machine to the operating room. ${ }^{9}$

One of the reliable methods for identification of perforators is angiography, but this is considered an invasive procedure and exposes the patient to radiation. Magnetic resonance angiography is a non invasive technique that can visualize the blood vessels exclusively. However, vessels smaller than $2 \mathrm{~mm}$ cannot be visualized accurately; thus such perforators are difficult to be detected by this method. ${ }^{5}$

The current study aims to map the perforators of the anterolateral thigh flap preoperatively using different diagnostic tools and to correlate the obtained results with the surgical findings.

\section{Patients:}

A prospective study was done through out two years from June 2005 till June 2007. Nine patients were included in the study; three of them females and six were males. The patients' ages ranged from 17-35 years. Routine preoperative investigations were done to exclude any associated medical problems. Determination of perforators in these patients in both thighs was done using doppler, color duplex and angiography followed by flap elevation from one side. The operative findings were compared to those of the preoperative assessment Table(1,2).

\section{Methods:}

Patients were placed in the supine position. The central axis of the flap was indicated by an imaginary line drawn from the ASIS to the superolateral border of the patella Figure(1). At the midpoint of this line, a circle with a 3$\mathrm{cm}$ radius was drawn to locate the perforators within the circle, especially in the lower outer quadrant. The perforators were then detected using the Doppler (handheld Doppler with a linear probe with a frequency of $8 \mathrm{MHz}$ ), color duplex (General Electric Logic 500 Duplex with a linear probe with a frequency range from 9-12 MHz) Figure(2) and angiography (PHILIPS angiography machine $\{2974\}$ MD3 ). All collected data was documented in the master sheet. The data collected included; number, site (vertically and horizontally), course, caliber and the relation to the site of the expected perforator.

The ALT flap was utilized as a free flap to cover defects in the face, hand and lower limb Table(1). In five patients the flap was raised from the right side and in the other four it was raised from the left side. The technique used for elevation of the ALT flap was similar to that described by Koshima et al., ${ }^{10}$ The flap was raised on the vascular pedicle with its perforator and accompanying vena comitantes.

The donor site in two cases was closed primarily while in the remaining cases a split thickness skin graft was applied. 
Table (1): Patients criteria.

\begin{tabular}{|c|c|c|c|c|}
\hline & Sex & $\begin{array}{c}\text { Age } \\
(\text { years })\end{array}$ & Diagnosis & Flap dimensions \\
\hline Case 1 & $q$ & 18 & $\begin{array}{l}\text { Unstable scar of the dorsum of the left } \\
\text { foot. }\end{array}$ & $16 \times 9 \mathrm{~cm}$ \\
\hline Case 2 & $q$ & 17 & Hemifacial atrophy (deepithelialized). & $17 \times 10 \mathrm{~cm}$ \\
\hline Case 3 & O & 18 & $\begin{array}{l}\text { Unstable scar of the dorsum and medial } \\
\text { side of the right foot with inversion. }\end{array}$ & $22 \times 9 \mathrm{~cm}$ \\
\hline Case 4 & d & 22 & $\begin{array}{l}\text { Unstable scar of the dorsum and medial } \\
\text { aspect of the left foot. }\end{array}$ & $35 \times 10 \mathrm{~cm}$ \\
\hline Case 5 & 1 & 20 & $\begin{array}{l}\text { Circumferential unstable scar of the } \\
\text { lower one third of the right leg. }\end{array}$ & $21 \times 10 \mathrm{~cm}$ \\
\hline Case 6 & d & 35 & $\begin{array}{l}\text { Post-burn scarring of the right side of } \\
\text { the face. }\end{array}$ & $25 \times 15 \mathrm{~cm}$ \\
\hline Case 7 & d & 29 & $\begin{array}{l}\text { Unstable scar of the dorsum and medial } \\
\text { side of the left foot. }\end{array}$ & $15 \times 9 \mathrm{~cm}$ \\
\hline Case 8 & d & 20 & $\begin{array}{l}\text { Skin loss of the dorsum of left hand with } \\
\text { exposed bone and extensor tendons. }\end{array}$ & $23 \times 10 \mathrm{~cm}$ \\
\hline Case 9 & 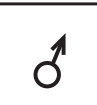 & 22 & $\begin{array}{l}\text { Unstable scar of the medial aspect of } \\
\text { lower one third of the left leg. }\end{array}$ & $30 \times 15 \mathrm{~cm}$ \\
\hline
\end{tabular}

\section{Results:}

The preoperative color duplex study performed bilaterally detected 14 perforators on the right thigh while angiography detected 12, and the Doppler located only five. The Doppler/duplex percentage was $35.7 \%$, while the angiography/duplex percentage was $85.7 \%$. On the left thigh, the duplex detected 12 perforators similar to the angiographic findings, while Doppler detected only six Table(3). The side of flap elevation had been chosen as regards the feasibility of elevation and pliability in application to the recipient site.

There was a statistically significant difference between the number of perforators detected by Doppler and those detected by duplex on both sides. No statistically significant difference between the number of perforators detected by angiography and those detected by duplex on both sides was present. Duplex study revealed that at least one perforator was found in each of the studied thighs with a total number of 13 perforators detected in the operated upon sides; six on the right side and 7 on the left side Table(2).

\section{- On the right side (4 patients):}

Six perforators were detected; two $(33.3 \%)$ were detected by both Doppler and color duplex while the other $4(66.7 \%)$ were detected only by duplex and angiography. The mean vertical distance from the ASIS was $23.33 \mathrm{~cm} \pm 7.66$ and the mean caliber of the perforators was $0.5 \mathrm{~mm} \pm 0.14$ Table(4). Four of the detected perforators were musculocutaneous while the other 2 were septocutaneous. As regards their relation to the expected perforator site, two were within the marked circle in the middle of the imaginary line while the other 4 were outside the circle Table(2).

- On the left side (5 patients):

Seven perforators were detected; three $(42.85 \%)$ perforators were detected by both Doppler and color duplex while the other four $(57.14 \%)$ were detected only by duplex and angiography. The mean vertical distance from the ASIS was $22.5 \mathrm{~cm} \pm 2.49$ and the mean caliber of the perforators was $0.48 \mathrm{~mm} \pm 0.07$ Table(4). Three of these perforators $(42.85 \%)$ were septocutaneous while the remaining 4 (57.14\%) were musculocutaneous. As regards 
the relation to the expected site of the perforator, three were found inside the marked circle in the middle of the imaginary line while the remaining four were found outside Table(2). Duplex findings \& measures of the perforators showed no statistically significant difference in the operated patients except for the mean length of the imaginary line Table(4).

All perforators detected by the preoperative duplex examination (13) were found intraoperatively. Twelve of them were found in the same site, number, course and caliber except in one patient (case 2) where the perforator was found in a location further away from the marked site Table(2). Eight of the perforators were musculocutaneous (61.5\%), passing through the vastus lateralis to reach the anterolateral thigh skin, while the other five were septocutaneous perforators $(38.5 \%)$ arising from the lateral circumflex artery and passing through the septum between the vastus lateralis and rectus femoris muscle to reach the anterolateral thigh skin. Tracing the perforator to the original feeding vessel was found helpful intraoperatively. The average time for flap elevation ranged from 2-3 hours in the case of septocutaneous perforators and from 3-4 hours when the perforator was musculocutaneous. Some of the operated cases are seen in Figures(3-5).

In the current study, the ALT flap was elevated in nine patients to reconstruct and solve various aesthetic and functional problems Table(1); eight flaps survived completely while one suffered partial sloughing of the distal 4$5 \mathrm{~cm}$ (case number 6). Three flaps suffered some vascular compromise in the early postoperative period which resolved on follow up.

Table (2): Operative data.

\begin{tabular}{|c|c|c|c|c|c|c|}
\hline & $\begin{array}{c}\text { Pedicle } \\
\text { length }\end{array}$ & $\begin{array}{c}\text { Number of } \\
\text { in the } \\
\text { operated } \\
\text { side }\end{array}$ & $\begin{array}{c}\text { Origin and type } \\
\text { of perforator }\end{array}$ & $\begin{array}{c}\text { Perforator } \\
\text { emergence } \\
\text { in relation } \\
\text { to the circle }\end{array}$ & $\begin{array}{c}\text { Correlation } \\
\text { between duplex } \\
\text { and operative } \\
\text { findings }\end{array}$ \\
\hline Case 1 & $13 \mathrm{~cm}$ & $2(\mathrm{Rt})$ & LCFA & $\mathrm{MC}$ & Outside & Coinciding \\
\hline Case 2 & $11 \mathrm{~cm}$ & $1(\mathrm{Rt})$ & LCFA & $\mathrm{MC}$ & Outside & Not Coinciding \\
\hline Case 3 & $13 \mathrm{~cm}$ & $2(\mathrm{Lt})$ & LCFA & $\mathrm{SC}$ & Inside & Coinciding \\
\hline Case 4 & $11 \mathrm{~cm}$ & $1(\mathrm{Rt})$ & $\begin{array}{c}\text { Femoral } \\
\text { artery }\end{array}$ & $\mathrm{MC}$ & Inside & Coinciding \\
\hline Case 5 & $10 \mathrm{~cm}$ & $2(\mathrm{Lt})$ & LCFA & $\mathrm{MC}$ & Outside & Coinciding \\
\hline Case 6 & $12 \mathrm{~cm}$ & $2(\mathrm{Lt})$ & LCFA & $\mathrm{MC}$ & Outside & Coinciding \\
\hline Case 7 & $10 \mathrm{~cm}$ & $1(\mathrm{Lt})$ & LCFA & $\mathrm{SC}$ & Inside & Coinciding \\
\hline Case 8 & $11 \mathrm{~cm}$ & $1(\mathrm{Rt})$ & LCFA & $\mathrm{SC}$ & Inside & Coinciding \\
\hline Case 9 & $13 \mathrm{~cm}$ & $1(\mathrm{Rt})$ & LCFA & $\mathrm{SC}$ & Outside & Coinciding \\
\hline
\end{tabular}

MC: Musculocutaneous, SC: Septocutaneous. 
Table (3): Number of perforators in both thighs detected by the different radiological methods.

\begin{tabular}{|c|c|c|c|}
\hline 9 patients & $\begin{array}{l}\text { Doppler } \\
\text { findings }\end{array}$ & $\begin{array}{c}\text { Duplex } \\
\text { findings }\end{array}$ & $\begin{array}{l}\text { Angiography } \\
\text { findings }\end{array}$ \\
\hline \multicolumn{4}{|l|}{ Right side: } \\
\hline Perforator Number & 5 & 14 & 12 \\
\hline Doppler/Duplex percentage & \multicolumn{3}{|c|}{$35.7 \%$} \\
\hline Angiography/Duplex Percentage & \multicolumn{3}{|c|}{$85.7 \%$} \\
\hline mean \pm SD & $0.67 \pm 0.5$ & $1.56 \pm 0.73$ & $1.33 \pm 0.87$ \\
\hline \multicolumn{4}{|l|}{ Left side: } \\
\hline Perforator Number & 6 & 12 & 12 \\
\hline Doppler/Duplex percentage & \multicolumn{3}{|c|}{$50 \%$} \\
\hline Angiography/Duplex Percentage & \multicolumn{3}{|c|}{$100 \%$} \\
\hline mean \pm SD & $0.56 \pm 0.73$ & $1.33 \pm 0.87$ & $1.33 \pm 0.87$ \\
\hline \multicolumn{4}{|l|}{ Both sides: } \\
\hline Perforator Number & 11 & 26 & 24 \\
\hline Doppler/Duplex percentage & \multicolumn{3}{|c|}{$42.3 \%$} \\
\hline Angiography/Duplex Percentage & \multicolumn{3}{|c|}{$92.3 \%$} \\
\hline
\end{tabular}

Table (4): Duplex measures of the perforators.

\begin{tabular}{|l|c|c|c|c|c|c|}
\hline \multirow{2}{*}{ Examined perforators } & \multicolumn{2}{|c|}{ Right Side } & \multicolumn{2}{c|}{ Left Side } & \multirow{2}{*}{ P value } & \multirow{2}{*}{ Sig } \\
\cline { 2 - 6 } & Mean & SD & Mean & SD & & \\
\hline Length $(\mathrm{cm})$ & 45.67 & 3.61 & 47.14 & 1.57 & -0.05 & S \\
\hline Vertical Site $(\mathrm{cm})$ & 23.33 & 7.66 & 22.50 & 2.49 & $>0.05$ & NS \\
\hline Site ratio & 0.50 & 0.14 & 0.48 & 0.07 & $>0.05$ & NS \\
\hline Horizontal site $(\mathrm{cm})$ & 0.50 & 0.14 & 0.48 & 0.07 & $>0.05$ & NS \\
\hline Caliber $(\mathrm{mm})$ & 0.50 & 0.14 & 0.48 & 0.07 & $>0.05$ & NS \\
\hline
\end{tabular}

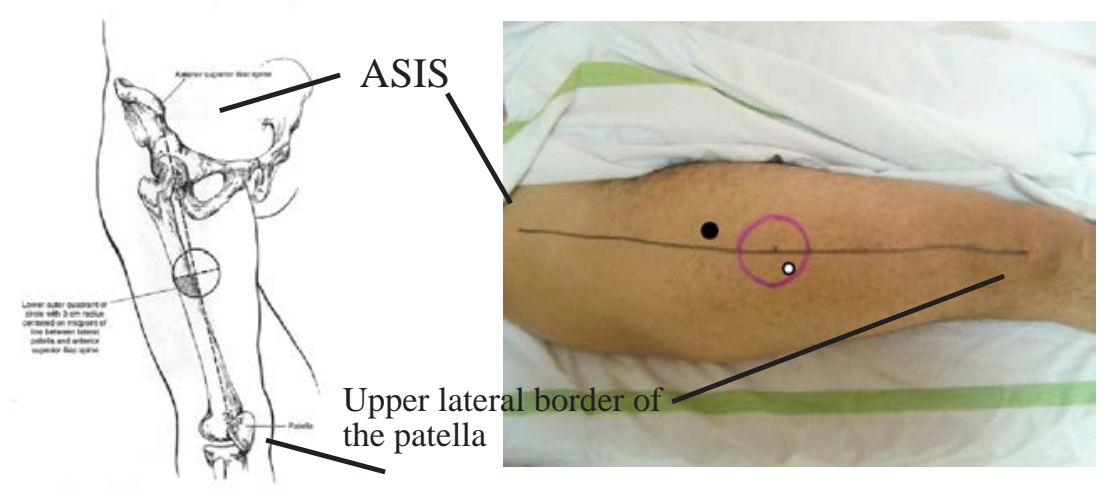

Figure (1): The diagram (left side) and the picture show the landmarks of the ALT flap in the right thigh with the marked sites of the perforators. Perforator detected by doppler and duplex.OExpected site of the perforator. 


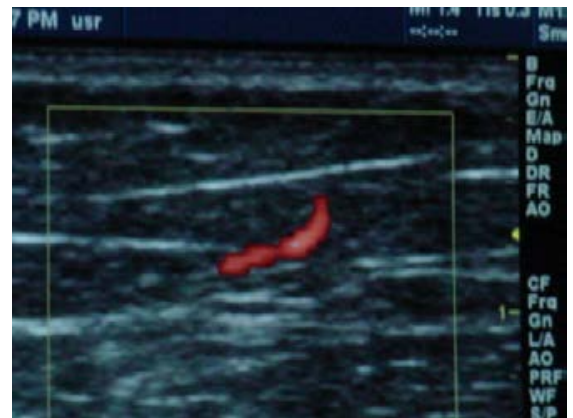

(A)

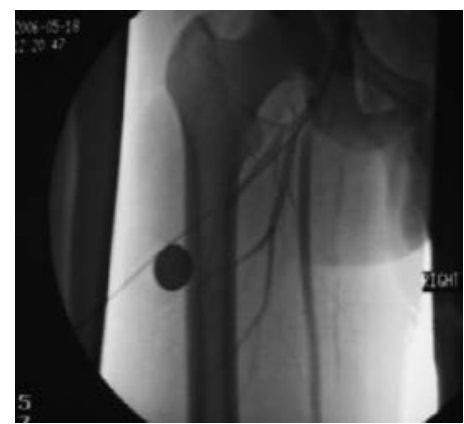

(B)

Figure (2): Preoperative detection of perforators; A) duplex examination of the perforator, $B)$ angiographic examination of the perforator).

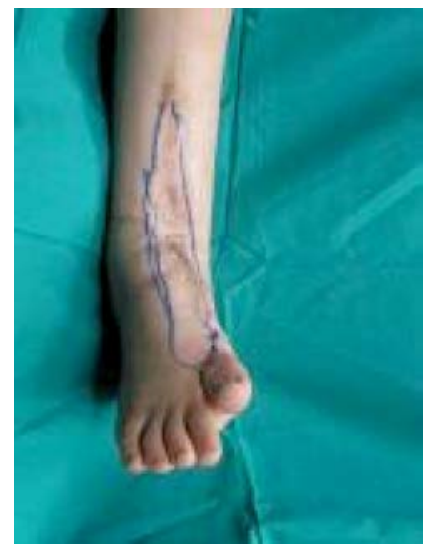

(A)

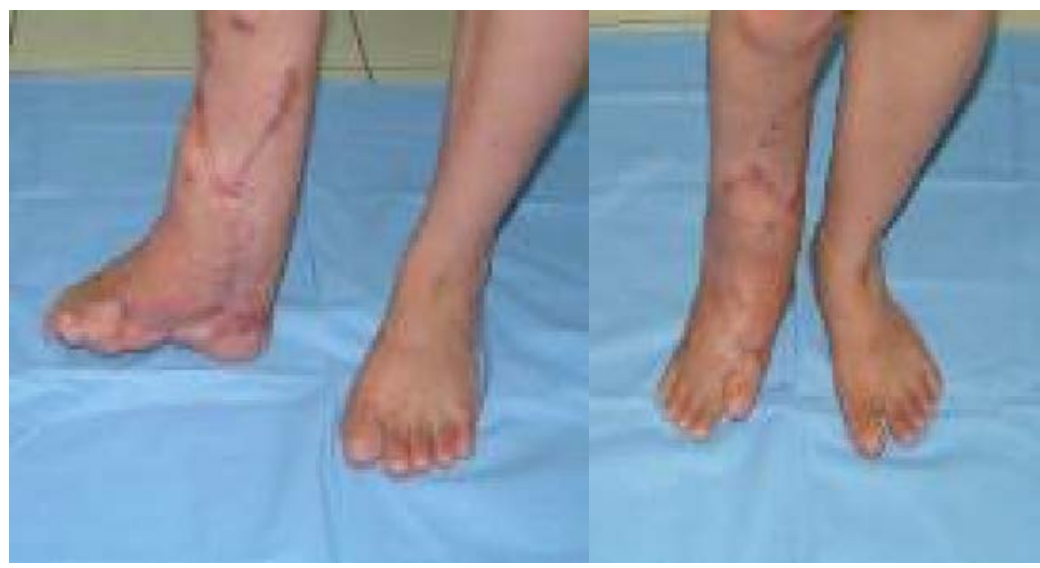

(B)

Figure (3): Case No.(3), A) Preoperative photo for a patient with unstable scar of the right foot, B) Late postoperative photos after one year.

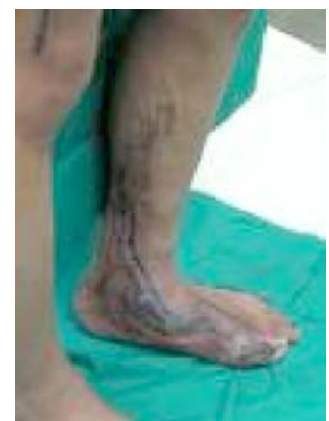

(A)

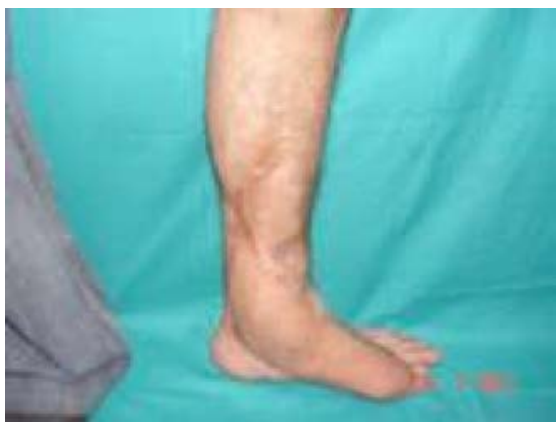

(B)

Figure (4): Case No.(4), A) Preoperative photo of a patient with unstable scar of the left foot, B) Postoperative photo for the patient after 10 months

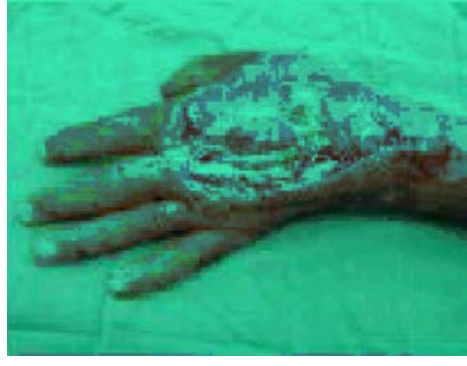

(A)

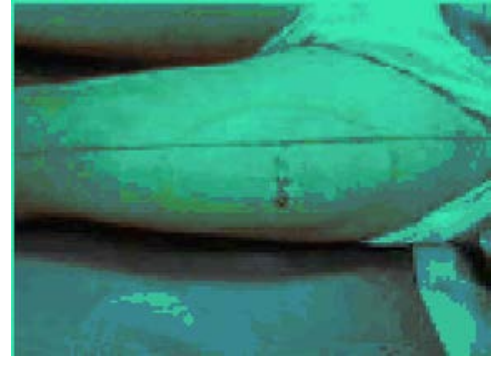

(B)

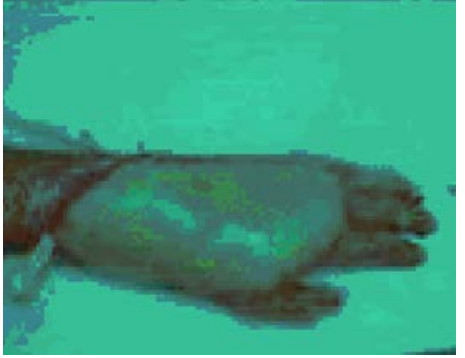

(C)

Figure (5): Case No.(8), A) Preoperative photo for the patient with skin loss of the dorsum of left hand with exposed bone and extensor tendons, B) Preoperative mapping of the perforators in the left thigh, $C$ ) Early postoperative photo. 


\section{Discussion:}

Perforator flaps have been developed to reduce donor site morbidity and limit the sacrifice of structures at the donor site, and to enable versatile design and thickness of the required flap. However, the main disadvantage of perforator flaps is that it requires a meticulous and challenging dissection. The presence of variability in the anatomy of the vascular supply of these flaps adds more to the difficulty of flap dissection.

Thigh flaps (especially the anteromedial and anterolateral thigh flaps) have many advantages. They are pliable, have a reliable blood supply and have a hidden donor site. Possible donor site primary closure and the sensory potential of these flaps are other advantages for such flaps. Despite these advantages, these flaps have not entered widespread use as the perforating arteries exhibit a wide range of anatomic variations adding to the difficulty of dissection. $3,7,11$

In the current study, the origin of the vascular pedicle was not found constant; in eight out of the nine $(88.8 \%)$ operated patients, the perforator was found arising from the descending branch of LCFA while in the remaining patient $(11.1 \%)$ the perforator was found arising directly from the femoral artery Table(2). These results are similar to those of Kiamata et al., ${ }^{12}$ yet contradicting those of Song et al., ${ }^{3} \mathrm{Xu}$ et al., ${ }^{13}$ Zhou et al. ${ }^{5}$ and Shieh et al. ${ }^{14}$ who reported that the perforator arises from the descending branch of LCFA only.

The septocutaneous perforators in the current study were found to represent $38.5 \%$, while the musculocutaneous perforators were $61.5 \%$. These results coincided with those of $\mathrm{Xu}$ et al., ${ }^{13}$ Shimizu et al. ${ }^{15}$ and Shaker ${ }^{16}$, yet were contradictory to the results of Kiamata et al., ${ }^{12}$ Shieh et al., ${ }^{14}$ Demirkan et al., ${ }^{11}$ Choi et al. ${ }^{18}$ and Wolff et al. ${ }^{19}$

The Doppler sonography is a compact, highly portable, simple to use, and relatively easy to interpret machine. In our study, the doppler detected five of the thirteen intraoperatively found perforators $(38.5 \%)$, a result consistent with previous reports done by Kiamata et al., ${ }^{17}$ Shieh et al., ${ }^{14}$ Giunta et al., ${ }^{20}$ and Tsukino et al., ${ }^{8}$ stating that doppler sonography in the preoperative detection of perforators is unreliable and carries a high false positive. Doppler to duplex detection ratio in both examined sides regardless of the intraoperative finding was $42.3 \%$, while the angiography to duplex detection ratio was $92.3 \%$. These results are similar to the studies done by Iida et al., ${ }^{1}$ and Tsukino et al. ${ }^{8}$

Data collected by the preoperative examination studies for the patients was compared to the intraoperative findings. All perforators detected by the preoperative duplex examination (totally thirteen) were found intraoperatively. Twelve of these perforators were found in the same site, number, course and caliber except in one patient where the perforator was found in a location further away from the marked site.

In the current study, the color duplex helped trace the perforator to the original vessel Table(2) complying with a similar report published by Blondeel et al., ${ }^{21}$ being the only study to report that the duplex can detect the source vessel. Such findings helped reduce the operative time for flap elevation since the surgeon could reach the targeted perforator easily and with a high accuracy rate.

\section{Conclusion:}

Color duplex study is a simple, easy and safe procedure for the patient, giving reliable informative preoperative data and meanwhile is affordable. The duplex examination alone can give the surgeon enough anatomical data needed for flap elevation, while angiography may be added for more details about the original vessel of the perforators. This method of preoperative evaluation leads to shortening of flap elevation time (2-3 hours in septocutaneous perforators and 3-4 hours in musculocutaneous perforators) since the site, number, course and caliber of perforators could be predicted preoperatively with high accuracy. Attendance of the operating surgeon during perforator mapping is advisable in order to achieve excellent and accurate duplex results (drawing guiding lines of each flap, precise marking of the perforators and identification of the course and caliber of the perforators). 


\section{References:}

1- Iida H, Ohashi I, Kishimoto S, Umeda T, Hata Y: Preoperative assessment of anterolateral thigh flap cutaneous perforators by color doppler flowmetry. $\mathrm{Br}$ J Plast Surg 2003; 56(1); 21- 25.

2- Chen HC, Tang YB: Anterolateral thigh flap: An ideal soft tissue flap. Clin Plastic Surg 2003; 30 (3); 383-401.

3- Song YG, Chen GZ, Song YL: The free thigh flap: A new free flap concept based on septocutaneous artery. Br J Plast Surg 1984; 37(2); 149-159.

4- Koshima I, H Fukuda, R Utunomiya, Soeda $\mathrm{S}$ : The anterolateral thigh flap: Variations in its vascular pedicle. Br J Plast Surg 1989; 42(3); 260-262.

5- Zhou G, Qiao Q, Chen GY, Ling YC, Swift R: Clinical experience and surgical anatomy of 32 free anterolateral; thigh flap transplantations. Br J Plast Surg 1991; 44(2); 91-96.

6- Koshima I, Hosoda M, Moriguchi T, Hamanaka T, Kawata S et al: A combined anterolateral thigh flap, anteromedial thigh flap and vascularized iliac bone graft for a full thickness defect of the mental region. Ann Plast Surg 1993; 31(2); 175-80.

7- Taylor G I, Doyle M, McCarten G: The doppler probe for planning flaps: An anatomical study and clinical applications. Br J Plast Surg 1990; 43(1): 1-16.

8- Tsukino A, Kurachi K, Inamiya T, Tanigaki T: Preoperative color doppler assessment in planning of anterolateral thigh flaps. Plast Reconstr Surg 2004; 113(1); 241246.

9- Giunta RE, Geisweid A, Feller AM: The value of preoperative doppler sonography for planning free perforator flaps. Plast Reconstr Surg 2000; 105(7); 2381-2386.

10-Koshima I, Kawada S, Etoh H, Kawamura $\mathrm{S}$, Moriguchi T, et al: Flow through anterior thigh flaps for one stage reconstruction of soft tissue defects and revascularization of ischemic extremities. Plast Reconstr Surg 1995; 95(2); 252-260.

11-Demirkan F, Che HC, Wei FC, Chen HH, Jung SG, et al: The versatile anterolateral thigh flap: A musculocutaneous flap in disguise in head and neck reconstruction. Br J Plast Surg 2000; 53(1); 30-36. 12-Kiamata Y, Uchiyama K, Ebihara S, Nakatsuka T, Harri K: Anatomic variations and technical problems of anterolateral thigh flap: A report of 74 cases. Plast Reconstr Surg 1998; 102(5); 1517-1523.

13-Xu DC, Zhong SZ, Kong JM, Wang GY, Liu MZ, et al: Applied anatomy of the anterolateral femoral flap. Plast Reconstr Surg 1988; 82(2); 305-310.

14-Shieh SJ, Chiu HY, Yu JC, Pan SC, Tsai ST, et al: Free anterolateral thigh flap for reconstruction of head and neck defects following cancer ablation. Plast Reconstr Surg 2000; 105(7); 2349-2357.

15-Shimizu T, Fisher DR, Carmichael SW, Bite U: An anatomic comparison of septocutaneous free flaps from the thigh region. Ann Plast Surg 1997; 38(6); 604610.

16-Shaker AA: Further description of the vascular anatomy of the free anterolateral thigh flap. Egypt J Plast Reconstr Surg 2002; 26(1); 85-94.

17-Kiamata Y, Uchiyama K, Ebihara S, Yoshizumi T, Asai M, et al: Versatility of the free anterolateral thigh flap for reconstruction of head and neck defects. Arc Otolaryngeal Head Neck Surg 1997; 123(12); 1325-1331.

18-Choi SW, Park JY, Hur MS, Park HD, Kang HJ, et al: An anatomic assessment on perforators of the lateral circumflex femoral artery for anterolateral thigh flap. J Craniofac Surg 2007; 18(4): 866-871.

19-Wolff KD, Grundmann A: The free vastus lateralis flap: Anatomic study with case reports. Plast Reconstr Surg 1992; 89(3); 469-475.

20-Giunta RE, Geisweid A, Feller AM: The value of preoperative doppler sonography for planning free perforator flaps. Plast Reconstr Surg 2000; 105(7); 2381-2386.

21-Blondeel PN, Beyens G, Verhaeghe R, Van Landuyt K, et al: Doppler flowmetry in the planning of perforator flap. Br J Plast Surg 1998; 51(3); 202-209. 